GSS, Vol.3, No.2 Juli - Desember 2021, Hal 170 - 177

ISSN 2655-3414 (print), eISSN 2685-2497

\title{
PEMBERDAYAAN PEREMPUAN MANDIRI DENGAN TEKNOLOGI DIGITAL MARKETING DI GAMPONG SUKAJADI KEBUN IRENG KECAMATAN LANGSA LAMA KOTA LANGSA
}

\section{EMPOWERING INDEPENDENT WOMEN WITH \\ DIGITAL MARKETING TECHNOLOGY IN GAMPONG SUKAJADI KEBUN IRENG KECAMATAN LANGSA LAMA KOTA LANGSA}

\author{
Tengku Putri Lindung Bulan ${ }^{1 *}$, Suri Amilia ${ }^{2)}$, Ziaul Maula ${ }^{3)}$ \\ ${ }^{1,2,3}$ Fakultas Ekonomi, Universitas Samudra, Jl. Kampus Meurandeh Aceh 24354 Indonesia \\ ${ }^{*}$ Penulis Korespodensi: tengkuputri@ unsam.ac.id
}

\begin{abstract}
ABSTRAK
Kondisi di tengah pandemi Covid-19 berdampak bagi kaum perempuan. Perempuan harus mampu memberdayakan dirinya secara optimal agar mereka dapat memberikan nilai tambah bagi keluarga. Kegiatan pengabdian kepada masyarakat ini dilaksanakan pada Gampong Sukajadi Kebun Ireng Kecamatan Langsa Lama Kota Langsa yang bertujuan: (1) untuk memberikan sosialisasi kepada ibu rumah tangga tentang penggunaan teknologi internet dan penggunaan metode-metode pemasaran berbasis teknologi digital marketing, (2) untuk memberikan motivasi pemanfaatan penggunaan metode-metode pemasaran berbasis teknologi digital marketing untuk berwirausaha, dan (3) pendampingan pembuatan media penjualan online. Kegiatan sosialisasi ini dilaksanakan dengan metode ceramah, praktek langsung, dan diskusi serta tanya jawab. Kegiatan ini diakhiri dengan evaluasi program kegiatan. Evaluasi kegiatan pengabdian ini dilakukan oleh Tim PKM bersama-sama masyarakat dan perangkat Gampong Sukajadi Kebun Ireng. Hasil yang dicapai adalah kegiatan pengabdian kepada masyarakat berjalan dengan baik dan lancar. Ini dapat dilihat dari antusiasme dan semangat peserta dalam mengikuti sosialisasi. Perangkat gampong dan para ibu rumah tangga sangat aktif dan ikut terlibat selama kegiatan sosialisasi ini berlangsung karena mereka ingin menjadi perempuan yang kuat, mandiri dan sejahtera agar dapat membantu perekonomian keluarga.
\end{abstract}

Kata Kunci : Teknologi Digital Marketing, Media Penjualan Online, Gampong Sukajadi Kebun Ireng

\begin{abstract}
Conditions in the midst of the Covid-19 pandemic have an impact for women. Women must be able to empower themselves optimally so that they can provide added value to the family. This community service activity was carried out at Gampong Sukajadi Kebun Ireng Kecamatan Langsa Lama Kota Langsa which aims: (1) to provide socialization to housewives about the use of internet technology and the use of digital marketing technology-based marketing methods, (2) to provide motivation utilization of marketing methods based on digital marketing technology for entrepreneurship, and (3) assistance in making online sales media. This socialization activity was carried out using the lecture method, direct practice, and discussion and question and answer. This activity ends with an evaluation of the program of activities. The evaluation of this service activity was carried out by the PKM Team together with the community and the Sukajadi Kebun Ireng Village apparatus. The result achieved is that community service activities run well and smoothly. This can be seen from the enthusiasm and enthusiasm of the participants in participating in the socialization. Village officials and housewives were very active and involved during this socialization activity because they wanted to become strong, independent and prosperous women in order to help the family economy.
\end{abstract}

Keywords : Digital Marketing Technology, Online Sales Media, Gampong Sukajadi Kebun Ireng 
GSS, Vol.3, No.2 Juli - Desember 2021, Hal 170 - 177

ISSN 2655-3414 (print), eISSN 2685-2497

\section{PENDAHULUAN}

Kondisi di tengah pandemi Covid-19 berdampak bagi kaum perempuan. Perempuan harus dihadapkan dengan berbagai tantangan baru, seperti Pemutusan Hubungan Kerja (PHK), beban ganda perempuan saat bekerja di rumah sekaligus mengurus anak yang belajar di rumah, potensi perempuan menjadi kepala rumah tangga meningkat, dan ancaman diskriminasi, eksploitasi, serta kekerasan, baik di lingkungan kerja maupun saat di rumah. Maka dari itu, perempuan harus mampu memberdayakan diri secara optimal agar mereka dapat memberikan nilai tambah bagi keluarga atau dengan kata lain menciptakan investasi bagi perempuan (Menteri Pemberdayaan Perempuan dan Perlindungan Anak: 2020), termasuk perempuan yang ada di Gampong Sukajadi Kebun Ireng, Kecamatan Langsa Lama, Kota Langsa Provinsi Aceh.

Melihat peran pentingnya kaum perempuan khususnya Ibu Rumah Tangga (IRT) maka perlu adanya upaya untuk memberikan "edukasi tentang teknologi digital marketing" di Gampong Sukajadi Kebun Ireng agar peran dan tugas kaum perempuan semakin kuat, mandiri dan sejahtera, sehingga dapat membantu perekonomian keluarga. Teknologi digital marketing merupakan suatu kegiatan pemasaran kepada target pasar melalui media internet. Dengan menggunakan media internet, jangkauan pasar menjadi luas.

Berdasarkan wawancara dengan Bapak Edi Putra, A.Ma selaku Geuchik Gampong Sukajadi Kebun Ireng menyatakan bahwa Gampong Sukajadi Kebun Ireng memiliki beberapa kegiatan usaha yang dihasilkan oleh penduduk setempat seperti: usaha kerajinan tangan, ternak ayam/itik, tambak lele, menjahit dan bordir, bengkel kendaraan, bengkel las, menjual aneka jenis makanan yang berupa makanan ringan dan jajanan, membuat peyek/bumbu pecal, membuat rengginang, menjual barang kelontong dan lain-lain. Namun, produk yang dihasilkan masih dijual hanya kepada penduduk sekitar saja. Para pelaku usahanya didominasi oleh ibu rumah tangga yang masih banyak melakukan kegiatan usahanya secara konvensional. Ada beberapa ibu rumah tangga yang masih gagap teknologi. Jika mereka menggunakan smartphone, masih dibantu oleh anaknya yang remaja. Mereka juga masih terkendala minimnya pengetahuan terhadap digital marketing. Padahal jika mereka melakukan kegiatan usahanya dengan digital marketing maka calon pembeli tidak hanya masyarakat sekitar saja, tetapi juga bisa menjangkau wilayah yang sangat luas sehingga dapat meningkatkan penjualan. 
GSS, Vol.3, No.2 Juli - Desember 2021, Hal 170 - 177

ISSN 2655-3414 (print), eISSN 2685-2497

Oleh karena itu, potensi dalam memanfaatkan digital marketing mengharuskan masyarakat Gampong Sukajadi Kebun Ireng untuk melek teknologi maka tim pengabdian kepada masyarakat berkeinginan untuk melakukan sosialisasi penggunaan teknologi digital marketing. Dengan adanya pemanfaatan teknologi digital marketing diharapkan dapat memberikan pengetahuan dan keterampilan serta menginspirasi para pelaku usaha terutama ibu rumah tangga dalam memanfaatkan teknologi internet dan media sosial sebagai alat untuk menjalankan kegiatan usahanya agar dapat memperluas pangsa pasar dan menumbuhkan jiwa wirausaha ibu rumah tangga sehingga dapat melakukan kegiatan bisnisnya lebih baik lagi.

\section{Analisis Situasional}

Gampong Sukajadi Kebun Ireng adalah sebuah gampong yang terletak di Kecamatan Langsa Lama, Kota Langsa, Aceh. Gampong ini diwujudkan pada tahun 2010 dari pemekaran Gampong Pondok Pabrik. Dalam kegiatan pengabdian ini melibatkan para ibuibu dari Dusun Pondok Tengah, Dusun Sukajadi, Dusun Makmur, Dusun Merak, dan Dusun Paya I. Ada beberapa permasalahan prioritas yang dihadapi mitra, yaitu:

1. Para pelaku usaha terutama ibu rumah tangga masih sangat terbatas dalam memanfaatkan penggunaan teknologi internet terutama teknologi digital marketing.

2. Masih minimnya pelatihan tentang penggunaan teknologi digital marketing yang dapat dimanfaatkan ibu rumah tangga yang berwirausaha membantu perekonomian keluarga. Kegiatan pengabdian dari para akademisi ataupun instansi pemerintahan dalam memberikan pelatihan di Gampong Sukajadi Kebun Ireng masih belum dilakukan secara optimal.

3. Masih kurangnya ilmu pengetahuan dan keterampilan tentang penggunaan teknologi internet dan teknologi Digital Marketing bagi ibu rumah tangga di Gampong Sukajadi Kebun Ireng. Dengan memanfaatkan teknologi internet dan teknologi digital marketing maka dapat membantu perekonomian keluarga.

Berdasarkan permasalahan tersebut ada 2 (dua) permasalahan yang harus segera diselesaikan, yaitu:

1. Dengan melakukan motivasi melalui pemanfaatan penggunaan teknologi internet dan teknologi digital marketing agar dapat memberdayakan para ibu rumah tangga Gampong Sukajadi Kebun Ireng yang berwirausaha mendukung kegiatan perekonomian keluarga.

2. Dengan melakukan pendampingan dalam pembekalan ilmu pengetahuan dan 
GSS, Vol.3, No.2 Juli - Desember 2021, Hal 170 - 177

ISSN 2655-3414 (print), eISSN 2685-2497

keterampilan tentang teknologi internet dan teknologi digital marketing sehingga ibu rumah tangga Gampong Sukajadi Kebun Ireng semakin kuat, mandiri dan sejahtera.

\section{METODE PELAKSANAAN}

Program ini diusul sebagai salah satu bentuk jawaban dari permasalahan belum tersedianya sumber daya manusia yang potensial dalam memanfaatkan penggunaan teknologi internet dan metode-metode pemasaran berbasis teknologi digital marketing guna untuk menumbuhkan semangat jiwa berwirausaha serta dapat meningkatkan perekonomian keluarga setempat.

Metode yang digunakan dalam kegiatan ini adalah metode penyuluhan dalam bentuk:

1. Sosialisasi dan pemaparan tentang penggunaan teknologi internet dan metodemetode pemasaran berbasis teknologi digital marketing, diskusi dan tanya jawab.

2. Pelatihan dan demonstrasi langsung dengan melibatkan peserta secara aktif.

3. Aplikasi hasil kegiatan pelatihan atau demonstrasi yaitu membuat media penjualan online baik melalui media sosial.

4. Pendampingan dalam menjalankan kegiatan usaha secara online.

\section{Gambar 1}

Metode Pelaksanaan

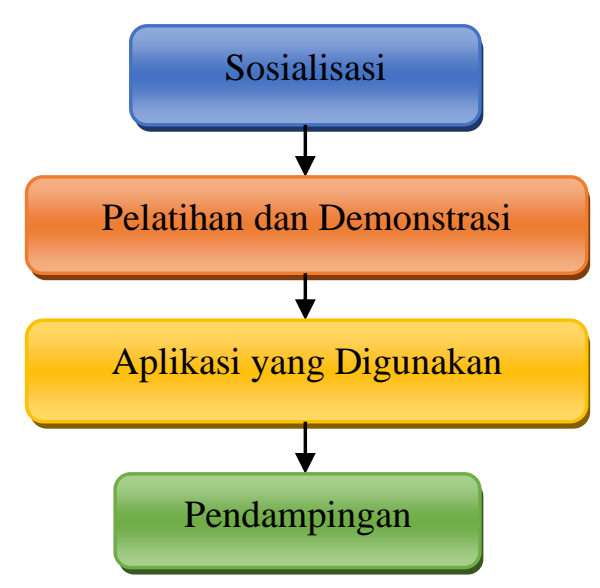

Materi yang diberikan kepada para peserta dilakukan baik melalui penyuluhan maupun diskusi dan tanya jawab yang meliputi: pengetahuan tentang penggunaan internet dan metode-metode pemasaran berbasis teknologi digital marketing. Melalui program ini, diharapkan ibu rumah tangga di Gampong Sukajadi Kebun Ireng mendapatkan pengetahuan dan wawasan yang jelas tentang pengetahuan penggunaan internet dan metode-metode pemasaran berbasis teknologi digital marketing bagi yang ingin berwirausaha ataupun yang sudah mempunyai kegiatan bisnis serta luaran dari hasil pengabdian kepada masyarakat ini diharapkan menjadi pengetahuan dan keterampilan dalam membantu kegiatan perekonomian keluarga khususnya, dan umumnya untuk mendukung perekonomian daerah.

\section{HASIL DAN PEMBAHASAN}

Sebelum kegiatan sosialisasi tentang penggunaan teknologi digital marketing dilaksanakan, Tim pengabdi terlebih dahulu 
GSS, Vol.3, No.2 Juli - Desember 2021, Hal 170 - 177

ISSN 2655-3414 (print), eISSN 2685-2497

melakukan survei di Gampong Sukajadi Kebun Ireng Kecamatan Langsa Lama Kota Langsa. Tim pengabdi melakukan wawancara kepada Bapak Edi Putra, A.Ma selaku Geuchik Gampong Sukajadi Kebun Ireng mengenai penggunaan teknologi digital marketing. Hasil analisis diperoleh bahwa respon Geuchik saat ditawarkan kegiatan tersebut disambut secara positif. Hal ini dilihat dari penyediaan sarana dari Gampong Sukajadi Kebun Ireng dan partisipasi aktif perangkat gampong dan masyarakat dalam mengikuti kegiatan tersebut sangatlah antusias.

Berdasarkan analisis potensi pelaksanaan kegiatan pengabdian kepada masyarakat bahwa ibu-ibu rumah tangga Gampong Sukajadi Kebun Ireng belum pernah mendapatkan sosialisasi tentang penggunaan teknologi digital marketing. Pada saat kegiatan dilakukan, ibu-ibu rumah tangga Gampong Sukajadi Kebun Ireng menganggap bahwa penggunaan teknologi digital marketing cukup sulit, mereka juga merasa tidak banyak transaksi aktual yang terjadi jika dibandingkan dengan berjualan secara langsung.

\section{Sosialisasi Teknologi Digital Marketing}

Kegiatan pengabdian masyarakat bertujuan untuk memanfaatkan penggunaan teknologi internet dan teknologi digital marketing agar dapat memberdayakan para ibu rumah tangga Gampong Sukajadi Kebun Ireng yang berwirausaha guna mendukung kegiatan perekonomian keluarga.

Kegiatan sosialisasi diawali dengan sambutan oleh Ketua Tim Pengabdi. Ketua Tim Pengabdi menyampaikan tujuan dan harapan serta adanya dukungan dari para peserta untuk berkomitmen dalam menjalankan kegiatan sosialisasi ini sampai selesai. Selain itu, Ketua Tim Pengabdi juga berharap adanya masukan dan saran dari peserta tentang pelaksanaan kegiatan pengabdian ini dan kegiatan pengabdian kepada masyarakat selanjutnya.

Geuchik Gampong Sukajadi Kebun Ireng yang diwakili oleh Bapak M. Nasir, S.E., selaku Kepala Dusun Merak Gampong Sukajadi Kebun Ireng dalam sambutannya menyatakan bahwa sangat mengapresiasi kegiatan pengabdian kepada masyarakat yang diselenggarakan oleh Dosen Fakultas Ekonomi Universitas Samudra. Bapak Nasir berharap kegiatan seperti ini dapat terus berlanjut dan memberi manfaat serta wawasan bagi para ibu rumah tangga Gampong Sukajadi Kebun Ireng.

Materi sosialisasi disampaikan pemateri yang termasuk salah seorang Tim PKM yaitu Bapak Ziaul Maula, S.E., M.Si. Materi yang disampaikan tentang penggunaan teknologi internet dan teknologi digital marketing. 
GSS, Vol.3, No.2 Juli - Desember 2021, Hal 170 - 177

ISSN 2655-3414 (print), eISSN 2685-2497

Pertama, pemateri menjelaskan tentang kegunaan teknologi internet dan teknologi digital marketing. Pemateri juga menjelaskan bahwa sebuah produk yang ingin dipasarkan harus memiliki merek dan kemasan yang baik dan menarik.

\section{Gambar 2}

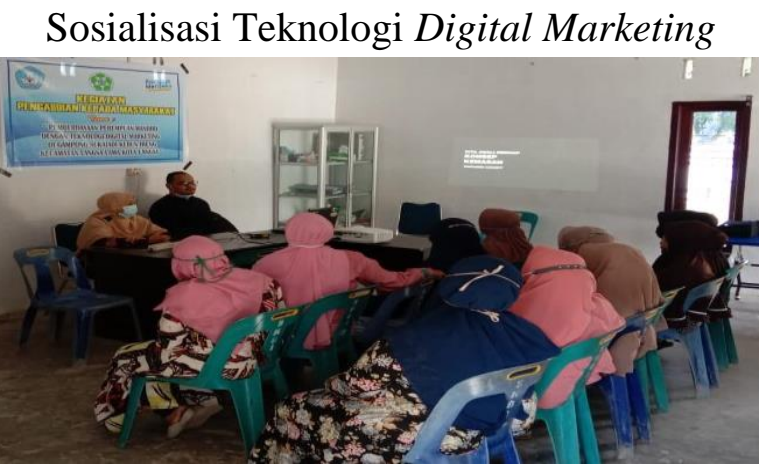

Selanjutnya, kegiatan kedua pemateri melakukan praktek langsung dan pendampingan tentang pembuatan Facebook Marketplace. Pemateri menjelaskan tata cara dan tips berjualan di Facebook Marketplace. Para peserta sangat antusias dan mereka diajak untuk melihat dan mengamati proses pembuatan Facebook Marketplace dengan baik dan benar.

\section{Gambar 3}

Tatacara Pembuatan Facebook Marketpalce
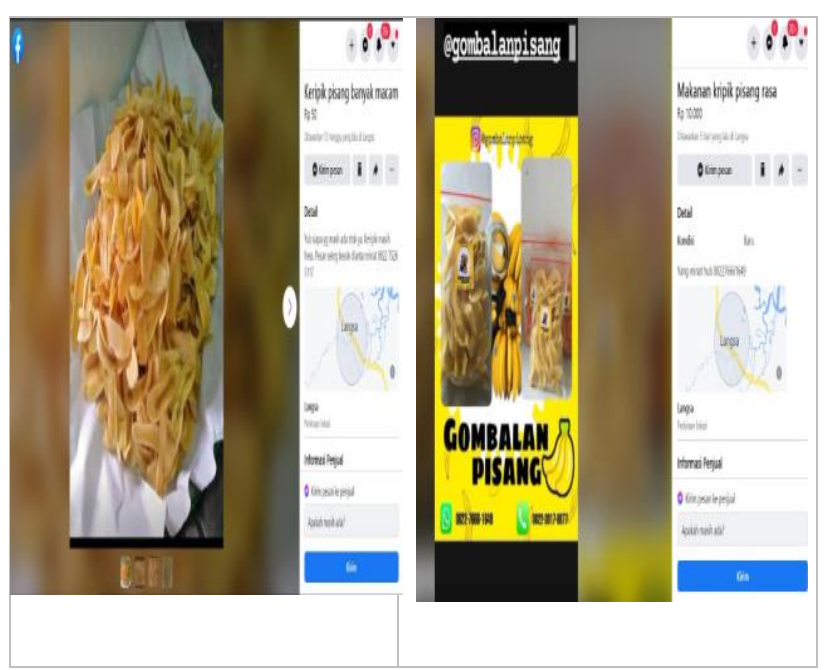

Setelah proses pembuatan Facebook Marketplace selesai maka kegiatan dilanjutkan dengan sesi diskusi. Dalam sesi diskusi diperoleh informasi bahwa dari 10 orang peserta, sebanyak 2 orang peserta yang pernah menggunakan media sosial untuk pemasaran produknya tetapi tidak mereka tekuni. Hal ini disebabkan mereka menganggap bahwa penggunaan digital marketing cukup sulit, mereka merasa tidak banyak transaksi yang benar-benar terjadi jika dibandingkan dengan memasarkan secara langsung. Sebanyak 8 orang peserta lainnya belum pernah menggunakan media sosial sebagai sarana pemasaran. Mereka masih malu-malu untuk mencoba karena tidak mengerti dengan cara pembuatan dan penggunaannya, meski ada pula yang merasa usahanya tidak membutuhkan pemasaran secara digital.

Selanjutnya, di sesi diskusi, salah seorang peserta "Pelaku Usaha Rengginang" yang bernama Ibu Ratna bertanya mengenai: 
GSS, Vol.3, No.2 Juli - Desember 2021, Hal 170 - 177

ISSN 2655-3414 (print), eISSN 2685-2497

"Bagaimana cara membuat merek suatu produk? Apakah harus ada surat izin usaha?

Kemudian pemateri menjawab bahwa merek itu merupakan sebuah nama atau tanda agar mudah dikenal oleh konsumen. Buatlah merek dengan desain dan kemasan yang menarik. Mulanya merek dapat dibuat melalui kertas stiker dengan mencantumkan narahubungnya lalu stiker tersebut ditempel di kemasan. Narahubung berguna agar konsumen mudah membeli kembali produk yang mereka inginkan. Untuk membuat merek jika usaha masih dalam skala kecil tidak perlu membuat surat izin usaha.

\section{Gambar 4}

Diskusi dengan Masyarakat

Gampong Sukajadi Kebun Ireng

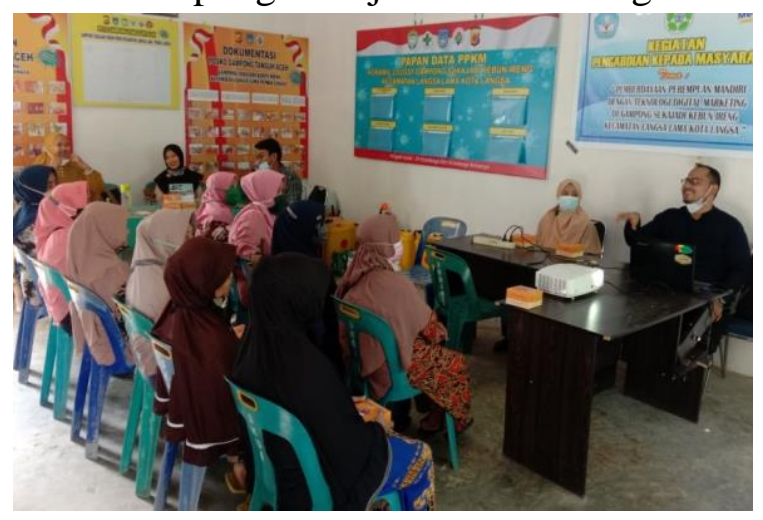

Dari hasil kegiatan sosialisasi dan praktek langsung serta pendampingan dapat berjalan dengan baik dan lancar. Hal ini dapat dilihat pada saat kegiatan para peserta mengikuti kegiatan secara antusias. Kegiatan yang dilakukan setelah sosialisasi adalah monitoring dan evaluasi program kegiatan. Evaluasi kegiatan pengabdian ini akan dilakukan oleh Tim PKM bersama-sama masyarakat dan perangkat Gampong Sukajadi Kebun Ireng, Kecamatan Lama, Kota Langsa. Evaluasi keberhasilan pelaksanaan kegiatan ini dilihat dari motivasi masyarakat dalam memanfaatkan penggunaan teknologi digital marketing agar dapat memberdayakan para ibu rumah tangga Gampong Sukajadi Kebun Ireng yang berwirausaha guna mendukung kegiatan perekonomian keluarga.

\section{SIMPULAN}

Berdasarkan hasil kegiatan pengabdian kepada masyarakat melalui kegiatan "Pemberdayaan Perempuan Mandiri dengan Teknologi Digital Marketing di Gampong Sukajadi Kebun Ireng Kecamatan Langsa Lama Kota Langsa” berjalan dengan baik dan lancar. Hal ini ditunjukkan dari antusiasme dan semangat peserta dalam mengikuti sosialisasi. Perangkat gampong dan para ibu rumah tangga sangat aktif dan ikut terlibat selama kegiatan sosialisasi ini berlangsung.

Diharapkan dengan adanya kegiatan pengabdian masyarakat ini dapat meningkatkan pemahaman pengetahuan dan keterampilan mitra mengenai penggunaan teknologi internet dan teknologi digital marketing sehingga ibu-ibu rumah tangga Gampong Sukajadi Kebun Ireng semakin kuat, mandiri dan sejahtera yang berguna untuk membantu kegiatan perekonomian 
GSS, Vol.3, No.2 Juli - Desember 2021, Hal 170 - 177

ISSN 2655-3414 (print), eISSN 2685-2497

keluarga khususnya, dan umumnya untuk mendukung perekonomian daerah.

Adapun saran yang dapat kami sampaikan setelah pelaksanaan pengabdian kepada masyarakat ini adalah:

1. Sosialisasi-sosialisasi seperti ini perlu dilaksanakan kembali untuk membangun kesadaran dan pemahaman mengenai digital marketing dan langkah-langkah yang harus dilakukan untuk membuat dan mengelola akun media sosial,

2. Materi yang disampaikan disesuaikan dengan kemampuan para peserta, serta

3. Adanya evaluasi lanjutan setelah kegiatan guna mengetahui apakah materi yang disampaikan benar-benar dipraktekkan.

\section{UCAPAN TERIMAKASIH}

Tim pengabdian mengucapkan terimakasih kepada Geuchik Gampong Sukajadi Kebun Ireng Kecamatan Langsa Lama Kota Langsa yang telah memberikan waktu, tenaga dan pikiran untuk terlaksananya kegiatan pengabdian kepada masyarakat tahun 2021 ini. Tim pengabdian juga mengucapkan terimakasih kepada masyarakat Gampong Sukajadi Kebun Ireng yang telah terlibat dalam pelaksanaan kegiatan "Pemberdayaan Perempuan Mandiri dengan Teknologi Digital Marketing” sebagai bagian dari pengabdian kepada masyarakat yang kami lakukan dalam melaksanakan tri darma perguruan tinggi.

\section{DAFTAR PUSTAKA}

https://blog.apjii.or.id/index.php/2020/11/09/s iaran-pers-pengguna-internet-indonesiahampir-tembus-200-juta-di-2019-q22020/

https://www.kemenpppa.go.id/index.php/page /read/29/2728/menteri-pppapemberdayaan-perempuan-investasiterbaik-bagi-dunia

Hidayat, Andi Nurul. 2018. "Perempuan Dalam Teknologi Digital Marketing Brand". Jurnal Musawa. Volume 10 nomor 1, Juni 2018. Hlm. 135-158.

Setiawan, Irwan dan Diani, Fitri. 2019. "Pemanfaatan Internet Marketing Untuk Mempersiapkan Masyarakat Kreatif dan Berjiwa Wirausaha Mandiri di Lingkungan Warga PKK". Jurnal Difusi. Volume 2 nomor 2, Juli 2019. Hlm. 45-53. 